\title{
DETERMINATION OF ARSENIC (III) BY DIFFERENTIAL PULSE POLAROGRAPHY IN THE WATERS OF CAMARONES AREA, CHILE
}

\author{
J.C.M.GAMBOA ${ }^{1,2}$, L. CORNEJO',3, J. ACARAPI² AND J.A. SQUELLA ${ }^{1 *}$ \\ 'Departamento de Química Orgánica y Fisicoquímica, Facultad de Ciencias Químicas y Farmacéuticas, Universidad de Chile, Casilla 233, Santiago 1, Chile. \\ ${ }^{2}$ Centro de investigaciones del hombre en el desierto (CIHDE), Arica, Chile - Conycit Regional R07F1001 \\ ${ }^{3}$ Departamento de Biología, Facultad de Ciencias, Universidad de Tarapacá, Arica, Chile.
}

(Received: July 29, 2013 - Accepted: October 2, 2013)

\begin{abstract}
As (III) was determined by differential pulse polarography (DPP) in $1 \mathrm{~mol} \mathrm{~L}^{-1} \mathrm{HCl}$ as supporting electrolyte. For quantification, the $-0.35 \mathrm{~V}$ peak (versus $\mathrm{Ag} /$ $\mathrm{AgCl})$ was chosen. The obtained detection and quantification limits were 2.7 (3 SD) and $8.9(10 \mathrm{SD}) \mu \mathrm{g} \mathrm{L} \mathrm{L}^{-1}$ respectively.

The method was used for the determination of As (III) on surface water samples from Camarones River, located in Camarones area, province of Arica, Chile (this area's water contain high levels of salinity). The results indicate that the proposed methodology is a suitable analytical alternative for As determination in natural waters with high levels of dissolved salts, as the waters of Camarones River. The method is not time consuming, nor tedious no prior treatment of the sample is required. The results show that As (III) concentrations in waters of Camarones River are about 10 times higher than the guide values established by WHO for water intended for human consumption.
\end{abstract}

Keywords: Arsenic (III), surface water, differential pulse polarography.

\section{INTRODUCTION}

The high toxicity of arsenic is related to its speciation; concentration increase may partly be associated to anthropic activities or geochemical natural processes. Arsenic (III) is the most toxic compound, when compared with arsenic (V) and its organic forms; therefore its determination is an important analytical challenge ${ }^{1}$. In terms of comparison between inorganic species, the trivalent state is approximately 60 times more toxic than the pentavalent form; on the other hand the organic compounds are 100 times less dangerous compared to inorganic compounds ${ }^{2}$. The direct exposure to arsenic has caused a big problem to public health in countries such as China, Mongolia, India, Bangladesh, Mexico, Taiwan, and Chile. It is the result of water consumption that is contaminated with this element ${ }^{2,3}$. In the northern part of Chile, in Camarones area (Province of Arica) high arsenic concentration have been found in the river, ranging from 1000 to $1300 \mu \mathrm{g} \mathrm{L}^{-1}$, thus considerably exceeding the maximum limits allowed by world health organization (WHO), for arsenic content in drinking water of $10 \mu \mathrm{g} \mathrm{L}^{-14}$. From the total values of arsenic present in the Camarones sector, the contribution of arsenic in its trivalent and pentavalent form is unknown. This means that no water speciation studies had been previously done in this region.

Prolonged consumption of water with high arsenic concentrations can cause diseases such as hyperkeratosis on feet and palms, skin cancer and other types of cancer affecting different organs ${ }^{3,4}$. The Arsenicosis manifests in corporal bioindicators on the skin of some people in Camarones area, being evident even to the naked eye. There are persons who lived in the area for about 50 years. The damage caused by arsenic in this person's skin is visible in the pictures. We can observe a skin alteration in relation to the normal morphology, affecting the individuals back and the epidermis thickness ${ }^{5}$.

The presence of high concentrations of arsenic and copper was determined in environmental matrixes such as river water, river sediments, and soils, in the surroundings of the Caletones smelter, in the VI Region of Chile ${ }^{6}$. This determination was carried out using Inductively Coupled Plasma-Optical Emission Spectrometer (ICP-OES) technique. The concentration of arsenic species in human hair was assessed in chronically As(V)-exposed populations from two villages (Esquiña and Illapata) of the Atacama Desert, Chile ${ }^{7}$. This study applied a relative simple method for arsenic speciation in human hair based on water extraction and High-perfomance liquid chromatography hydride generation inductively coupled plasma-mass spectrometry (HPLC-HG-ICPMS). Both of the above techniques have the advantage of being very sensitive and reproducible techniques, but with a high cost and indirect determination in its speciation. Due to this, the electrochemical techniques emerge with the purpose of eliminating the disadvantages of these high-cost techniques. As main advantages we can mention: simple sample preparation, high sensitivity, good selectivity, trace metal determination, direct determination of speciation and easy miniaturization; this makes the transportation to remote regions easier, and therefore gives the possibility to make in-situ measurements in real time ${ }^{8}$.

There are electrochemical techniques for the determination of trace metals. Cathodic (CSV) and anodic (ASV) stripping voltammetry is one of the most common for this goal. S. Yilmaz et al ${ }^{9}$ published an anodic stripping voltammetry (ASV) determination method for As in natural water samples using gold rotatory electrode. Most of the research related to gold electrodes use ASV for the determination of Arsenic (III) but Kristoff Gibbon - Walsh and collaborators, used CSV for the determination of arsenic III, in a gold microwire. This is an alternative to determine this specie in non-acid solutions $\mathbf{s}^{10}$.

The gold surface has reproducible and reliable results, for that reason there is abundance of work done related to the As determination ${ }^{11-19}$.

Certainly gold is less toxic than mercury, but mercury will always be an important alternative for the determination of trace metals. Taking all the necessary precaution to work with it polarography could be used with no problems.

One of the best electrodes for trace metals determination is the hanging mercury drop electrode (HMDE). The HMDE offers the advantage of continuous renewal of the electrode surface, and it is even possible to use it as static mercury drop electrode (SMDE) for which a minimal amount of mercury is used ${ }^{20-31}$.

CSV is used to determine low concentrations of As, it is necessary to carry out the As (III) deposition in the surface of mercury, the formation of an intermetallic compound, being $\mathrm{Cu}^{29,31}$ and $\mathrm{Se}^{28}$ used for this purpose. DPP is one of the most versatile techniques because it possesses a high resolution, allowing the determination of As (III) without the addition of external reagents and pretreatment of the samples ${ }^{32}$. However the As speciation can be affected by interferences like $\mathrm{Pb}, \mathrm{Sn}$ and TI that could be present in a real sample ${ }^{32-33}$ this phenomenon will be clearly limited to the amount of As contained in the sample.

David J. Myers investigated the determination of As (III) by DPP, and conducted a study of different supporting electrolytes, where $1 \mathrm{~mol} \mathrm{~L}^{-1} \mathrm{HCl}$ was considered to have greater sensitivity ${ }^{34}$.

The aim of this work is the determination of As (III) in surface waters in Camarones river, province of Arica (Chile), by DPP technique due to high concentrations of As (III). The information we possess regarding the levels of As (III) in this region is still insufficient ${ }^{3}$, specifically because costs involved, and the fact that necessary equipment is not available in the region. That is why this electrochemical technique emerges as an important tool for As speciation in the Camarones area.

\section{EXPERIMENTAL SECTION}

2.1. Chemicals, materials and samples

All reagents were of analytical grade. Milli-Q water (Millipore, Bedford, 
MA) was used for all experiments. The concentrated $\mathrm{HCl}$ used throughout the experiments was of p.a.-plus grade, $30 \% \mathrm{w} / \mathrm{w}, \mathrm{d}=1.16 \mathrm{Kg} \mathrm{L}^{-1}$. The 1000 $\mathrm{mg} \mathrm{L}^{-1}$ As (III) stock solution was prepared by dissolving $0.1320 \mathrm{~g}$ of arsenic trioxide in $1 \mathrm{~mL}$ of $25 \% \mathrm{NaOH}$, acidified immediately with $2 \mathrm{~mL}$ concentrated $\mathrm{HCl}$ and diluted to $100 \mathrm{~mL}$ with deionized water. All reagents were purged with nitrogen. Samples of water were filtered $(0.45 \mathrm{~nm})$ and preserved at $4^{\circ} \mathrm{C}$. The samples were taken from four different spots in the Camarones Valley (river water). $10 \mathrm{~mL}$ aliquot for each sample was taken to make the corresponding analysis.

\subsection{Electrodes and instrumentation}

Electrochemical measurements were recorded on the Electrochemical Analyzer BAS 100W (Bioanalytical System) attached to a desktop computer with the appropriate software (BAS 100W 2.3 for Windows) for total control of the experiments and data acquisition and treatment. Experiments were done in a conventional electrochemical cell using a $\mathrm{Ag} / \mathrm{AgCl}$ (saturated $\mathrm{KCl}$ ) as the reference electrode and a platinum wire as the counter electrodes, and the working electrode which can be used either in the hanging mercury drop mode or as a controlled-drop as a dropping mercury electrode.

\section{RESULTS AND DISCUSSION}

The determination of arsenic and other metals will always be influenced by the use of supporting electrolyte, where $1 \mathrm{~mol} \mathrm{~L}^{-1} \mathrm{HCL}$ is used as the most efficient due to its sensitivity for the determination of As (III) by DPP technique ${ }^{32}$.
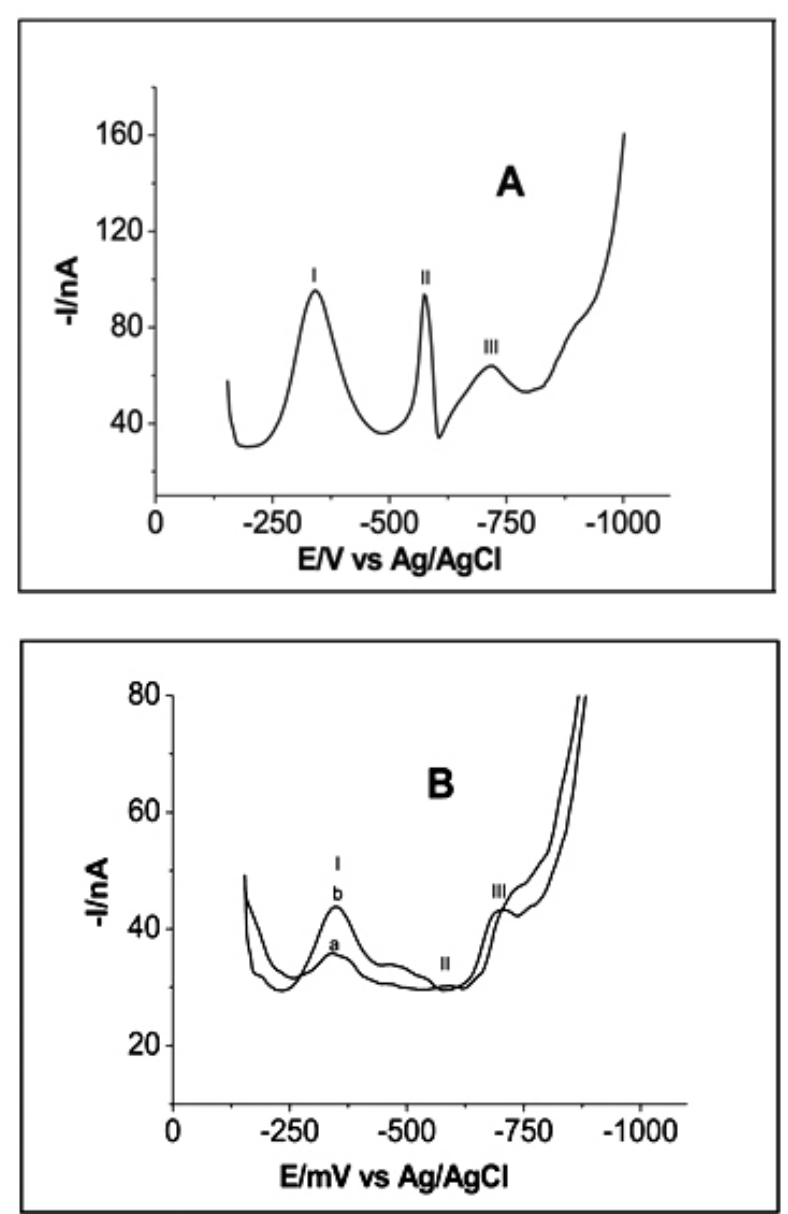

Figure 1-. DPP (A) of $500 \mu \mathrm{g} \mathrm{L}{ }^{-1}$, (B) 50 (a), 100 (b) of As (III) $\mu \mathrm{g} \mathrm{L} \mathrm{L}^{-1}$ $+1 \mathrm{~mol} \mathrm{~L}{ }^{-1} \mathrm{HCl}$ solution. Scan rate: $4 \mathrm{mV} / \mathrm{s}$, pulse amplitude: $25 \mathrm{mV}$, sample width: $20 \mathrm{~ms}$, pulse width: $50 \mathrm{~ms}$.
As shown in Figure 1A, the polarogram consists of 3 peaks by DPP in acidic solutions. The $-340 \mathrm{mV}$ peak (versus $\mathrm{Ag} / \mathrm{AgCl}$ ) has a higher current signal, and it was chosen for quantification, since it has a linear dependence with the As concentration. This peak is due to the reduction of As (III) to elemental As. The third peak $(\approx-720 \mathrm{mV})$ is related to the reduction of As $(0)$ to Arsine $\left(\mathrm{AsH}_{3}\right)$. This peak is not used for quantification because it has a very negative potential (greater probability of interference) and a low current signal, which can lead to poor sensitivity.

The second peak $(\approx-580 \mathrm{mV})$ can be attributed to a polarographic maximum, that disappear if As (III) concentrations are decreased to 50 (Figure $1 \mathrm{Ba})$ or $100 \mu \mathrm{g} \mathrm{L}^{-1}$ (Figure 1Bb). The use of surfactant can help in removing this polarographic maximum, but it may influence the $-340 \mathrm{mV}$ peak sensitivity (the peak of interest) causing unfavorable changes in the positions of peaks, which makes this a negative strategy ${ }^{31}$. It is hard to determine the exact cause of a polarographic maximum, but generally it can be attributed to the tangential movements the surface of the mercury drop has, from the base to the neck/top, opposing itself to its radial growth ${ }^{35}$.

It is important to mention that no reduction peak of the As (V) was observed, because it is not electroactive in this interval of potential.

The parameters involved in DPP technique were studied in order to increase the analytical sensitivity of the methodology for As (III) determination.
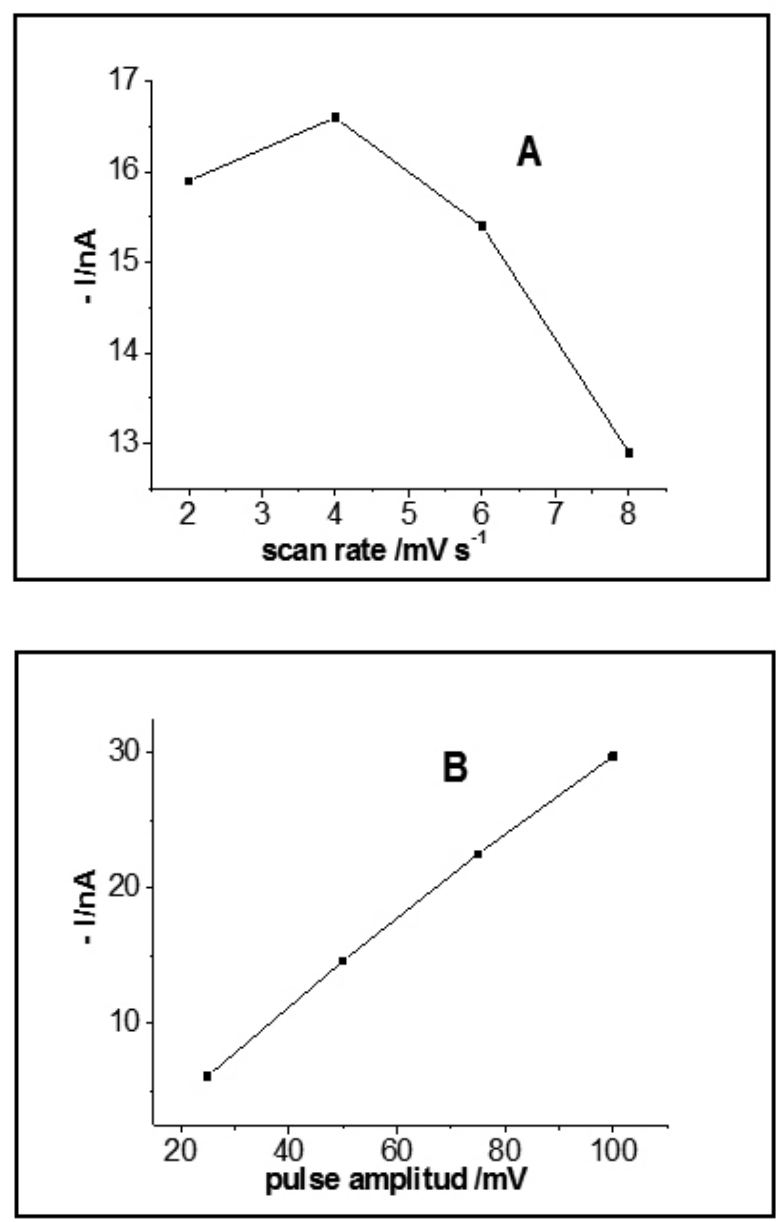

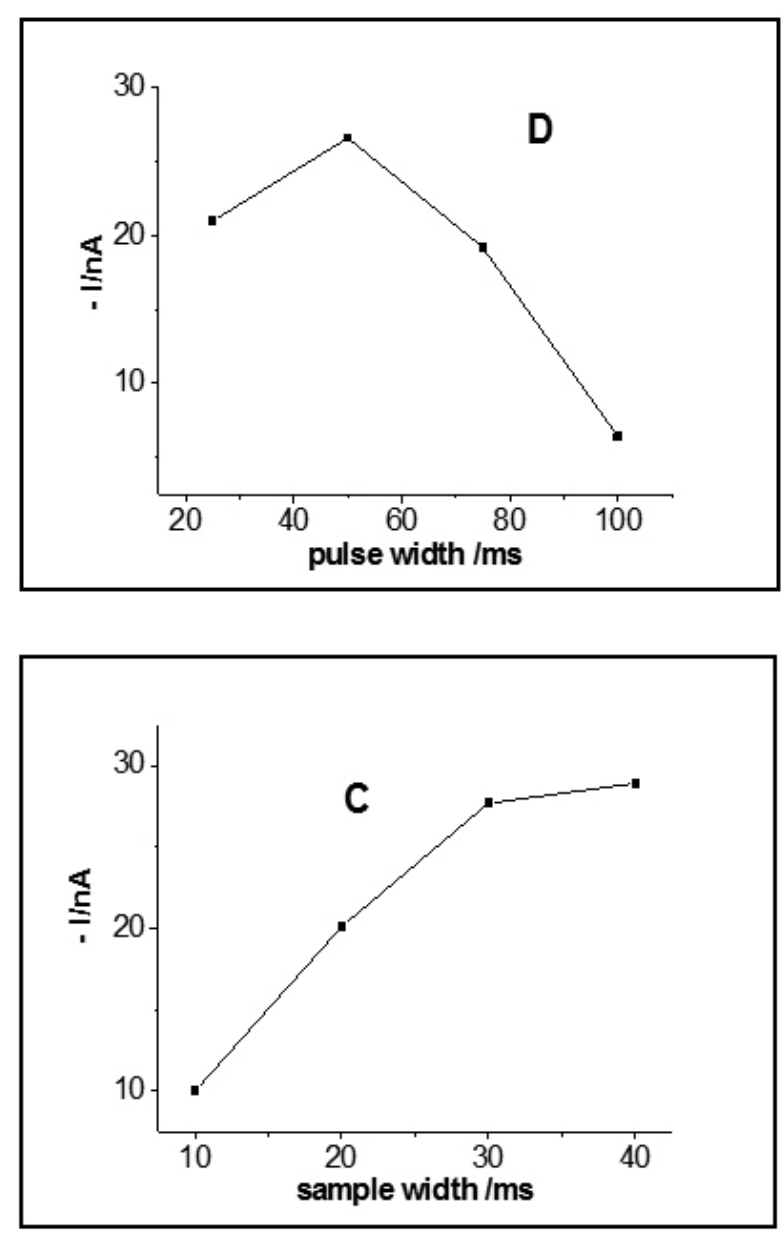

Figure 2-. Peak current values obtained by DPP in $250 \mu \mathrm{g} \mathrm{L}^{-1} \mathrm{As}(\mathrm{III})+1$ mol L-1 $\mathrm{HCl}$ solution. The Curves represent the parameters of (A) scan rate, (B) pulse amplitude, (C) sample width, (D) pulse width. Drop Time: $1000 \mathrm{~ms}$. Quit time: $0 \mathrm{~s}$.

As it is shown in Figure 2, the optimum parameters were chosen in relation to the highest intensity signal. The obtained results were the following: Figure 2A scan rate: $4 \mathrm{mV} \mathrm{s}^{-1}$, Figure 2B pulse amplitude $100 \mathrm{mV}$; Figure 2C sample width $40 \mathrm{~ms}$; and Figure 2D pulse width $50 \mathrm{~ms}$.

From this research, due to the polarogram characteristics, the pulse amplitude parameter is very important (Figure 2) because it present 3 peaks, which can be affected by this parameter. By increasing the pulse amplitude, a proportional current increase occurs. This increase of the parameter has its restrictions, due to the widening of the current peaks, influencing the accuracy of analytical results and also the resolution. By using greater amplitudes, adjacent peaks can be overlapped; therefore the choice of this parameter must be a commitment of increasing sensitivity, without resolution losses. For this reason, $100 \mathrm{mV}$ was selected as the value that fulfills the above mentioned conditions.

The relation between the current and arsenic (III) concentration was studied between $0.049-14.68 \mathrm{mg} \mathrm{L}^{-1}$ from polarograms obtained between -0.15 to $-0.55 \mathrm{~V}$ vs $\mathrm{Ag} / \mathrm{AgCl}$. The use of optimal conditions previously informed generated a linear response: $-\mathrm{I}(\mathrm{nA})=17+75.08[\mathrm{As}(\mathrm{III})] \quad\left(\mu \mathrm{g} \mathrm{L}^{-1}\right.$ )], $\mathrm{R}^{2}=0.9992$ (Figure 3). The repeatability of the determinations was of $8.6 \%$ $(\mathrm{n}=10)$ at the level of $0.4 \mathrm{mg} \mathrm{L}^{-1}$ in the optimal conditions previously described. The limits of detection and quantification were estimated at 2.7 (3 SD) and 8.9 (10 SD) $\mu \mathrm{g} \mathrm{L}^{-1}$ respectively.

The DPP techique was applied for waters extracted from Camarones River, in Camarones Valley, Arica and Parinacota Region, North of Chile.

Camarones was selected for As speciation study due to high rates of total As in the region $\wedge 4$. Camarones has approximately 200 inhabitants, and its population is $100 \%$ rural. One of the disadvantages that this population faces, is that there is no potable water available, which real necessity depends on the domestic, social and productive characteristics. Hence, the water supply is mainly from rivers and waterfalls.

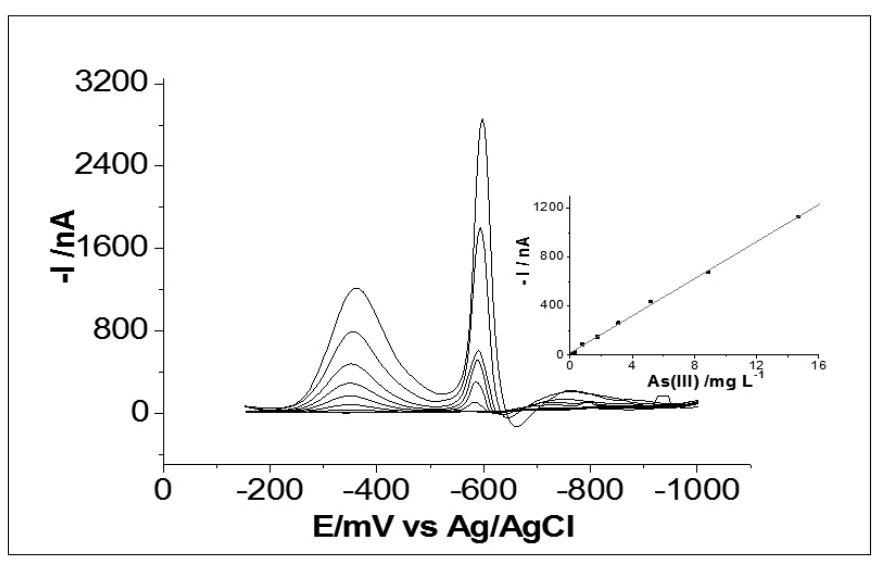

Figure 3-. DPP obtained in $1 \mathrm{~mol} \mathrm{~L}^{-1} \mathrm{HCl}$ solution after the addition of $\mathrm{As}(\mathrm{III})$ in order to give a final concentration of solution in an interval between $0.049-14.68 \mathrm{mg} \mathrm{L}^{-1}$ (peak at $-0.34 \mathrm{~V}$ ). The inserted graph corresponds to an analytical curve obtained on the basis of the current peaks observed in the DPP curves.

In Camarones, 4 specific spots (river water) were sampled, which comprises a large extension of water access site of this population.

River water samples were chosen, because it is the most important and main water source in the area. it is indispensable for agricultural activity, cattle farming, human consumption and all life beings. This area consists on a hydric system that can vary in several spots, related to the amount of minor water sources such as watersheds. That is why is so important to sample different spots on the area.

The Camarones valley inhabitants are mostly disperse and isolated, for which having access to a potable water source is very difficult. The closest potable water sources are available in Arica, a city located $77 \mathrm{~km}$ (47.7 miles).

These samples are river water type without treatment (non potable), from spots in which the population is likely to use it or consume it. The Figure 4 clearly indicates the distribution in different spots of this location, covering a wide scan of the sector.

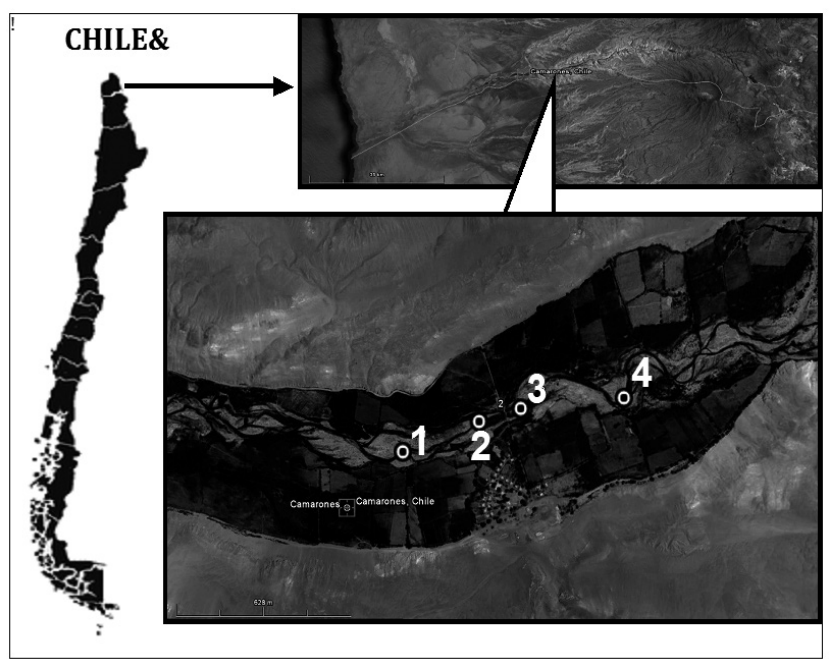

Figure 4-. Identification of water sampling spots, extracted from Camarones River, Camarones Valley, Arica and Parinacota Region, North of Chile. 
Table 1-. Analysis of Arsenic (III) for DPP in water samples from Camarones River, Camarones Valley, Arica and Parinacota region, North of Chile (N=3).

\begin{tabular}{|c|c|c|c|c|c|}
\hline Samples & $\mathrm{pH}$ & $\begin{array}{c}\text { Conductivity } \mu \mathrm{S} \\
\mathrm{cm}^{-1}\end{array}$ & $\begin{array}{l}\text { Total dissolved } \\
\text { solids } \mathrm{mg} \mathrm{L}^{-1}\end{array}$ & Location & As (III) ug $L^{-1}$ \\
\hline 1 & 8.41 & 2905 & 2050 & $\begin{array}{c}19 \mathrm{~K} 409131.81 \mathrm{~m} \mathrm{E} \\
7897909.33 \mathrm{~m} \mathrm{~S}\end{array}$ & $104.8 \pm 5.3$ \\
\hline 2 & 8.22 & 2230 & 2005 & $\begin{array}{c}19 \mathrm{~K} 409424.14 \mathrm{~m} \mathrm{E} \\
7898015.57 \mathrm{~m} \mathrm{~S}\end{array}$ & $65.8 \pm 3.3$ \\
\hline 3 & 8.35 & 2310 & 1950 & $\begin{array}{c}19 \mathrm{~K} 409583.10 \mathrm{~m} \mathrm{E} \\
7898061.10 \mathrm{~m} \mathrm{~S}\end{array}$ & $73.9 \pm 7.1$ \\
\hline 4 & 8.33 & 2581 & 2002 & $\begin{array}{c}19 \mathrm{~K} 409975.48 \mathrm{~m} \mathrm{E} \\
7898099.77 \mathrm{~m} \mathrm{~S}\end{array}$ & $90.1 \pm 5.2$ \\
\hline
\end{tabular}

One of the major uncertainties of this sector was to find the As (III) input, due to its great toxicity. The electrochemical technique has the advantage of direct speciation and it was selected for As (III) determination.

A recovery study was conducted as a way to prove the accuracy of this method, by adding As (III) to the river water sample. The recovery results were satisfactory, in an interval of 85 to $93 \%$. This indicates that the samples do not require a prior treatment in order to be analyzed.

The natural water used in this research corresponds to the one extracted from Camarones river, these are characterized by their high levels of salinity, this is manifested through the high level of electric conductivity and total dissolved solids (Table 1). These high levels of dissolved salts in the waters of Camarones River have already been informed by other authors indicating also high amounts for other disolved species, such as sulfates and chlorides ${ }^{4}$. These high levels of dissolved salts have conditioned the social and economic development of the region, because of the high levels of boron and salts presented as specific toxics, allowing successful growth of only resistent harvest (corn and alfalfa). On the other hand, the electrochemical methodology proposed presents interference reported by the presence of aqueous species like $\mathrm{Pb}(\mathrm{II})$ which are practically absent in the waters of Camarones River $(<0.05 \mathrm{mg}$ $\left.\mathrm{L}^{-1}\right)^{4}$. Table 1 shows that As (III) concentrations rank in an interval of $65-104$ $\mu \mathrm{g} \mathrm{L}{ }^{-1}$. So we can see that the samples contain a higher amount to the standard, which can be harmful to the health of the inhabitants of the study area. It is noteworthy that it is not possible to make a comparison of results related to Camarones Valley sector because the results exposed are the first in the area, which is why the results shown in this work are so important.

\section{CONCLUSIONS}

The most important contribution of this work is related to the determination of As (III) content in the water of Camarones River, from Camarones Valley, Arica and Parinacota region, Northern Chile; waters that feature high dissolved salts content, some of which are presented as specific interference in the determination of As through other analytical techniques.

The results indicate the great amount of As in an interval from $65-104 \mu \mathrm{g}$ $\mathrm{L}^{-1}$, corresponds to a 10 times higher than standard drinking water (WHO). We can state found concentrations of this species are extremely high, which can affect the quality of life and health of Camarones' population; for that reason, it is necessary to strengthen public health in order to seek control mechanisms, as it can have a physical, social and mental effect on the community.

\section{ACKNOWLEDGEMENTS}

This work was supported by grant from FONDECYT 3120040.

\section{REFERENCES}

1. R. Piech, and W. W. Kubiak, J. Electroanal. Chem. 59, 599, (2007)

2. A. Cavicchioli, M. A. La-Scala, and I. G. R. Gutz, Electroanal. 697, 16, (2004)

3. J. Yañez, V. Fierro, H. Mansilla, L. Figueroa, L. Cornejo, and R. M. Barnes, J. Environ. Monit. 1335, 7, (2005)
4. L. Cornejo, H. Lienqueo, M. Arenas, J. Acarapi, D. Contreras, J. Yañez, and H. D. Mansilla, Environ. Pollut. 827, 156, (2008)

5. AICD, Prospect of rural latin American Communities for application of low-cost technologies for water potabilization. Ed. Marta Litter, 2001 ; pp. 47-49

6. P. Richter, R. Seguel, I. Ahumada, R. Verdugo, J. Narváez and Y. Shibata, J. Chil. Chem. Soc. 333, 49, (2004)

7. J. Yáñez, V. Fierro, H. Mansilla, L. Figueroa, L. Cornejo and R. M. Barnes. J. Environ. Monit., 7, 1335, (2005)

8. R. Feeney and S. P. Kounaves, Anal. Chem. 72, 2222, (2000)

9. S. Yilmaz, B. Baba, A. Baba, S. Yagmur, and M. Citak, Curr. Anal. Chem. 29, 5, (2009)

10. K. Gibbon - Walsh, C.M.G. Van den Berg, Anal. Chim. Acta 662, 1, (2010)

11. G. Forsberg, J. W. O'Laughlin, and R. G. Megargle, Anal. Chem. 1586, 47, (1975)

12. P. Salaün, B. Planer-Friedrich, and C. M. G. Van den Berg, Anal. Chim. Acta 312, 585, (2007)

13. R. Prakash, R. C. Srivastava, and P. K. Seth, Electroanal. 1410, 15, (2003)

14. A. I. Kamenev, A. B. Lyakhov, and S. E. Orlov, J. Anal. Chem. 156, 60, (2005)

14. Y. Song, and G.M. Swain, Anal. Chem. 2412, 79, (2007)

16. S. C. Paul, M. A. Rahman, N. Siddique, and A. M. S. Alan, Pak. J. Environ. Chem. 49, 9, (2008)

17. L. Xiao, G. G. Wildgoose, and R. G. Compton, Anal. Chim. Acta 44, 620, (2008)

18. X. Dai, G. G. Wildgoose, C. Salter, A. Crossley, and R. G. Compton, Anal. Chem. 6102, 78, (2006)

19. E. Majid, S. Hrapovic, Y. Liu, K. B. Male, J. H. T. Luong, Anal. Chem. 762, 78, (2006)

20. Y. He, Y. Zheng, M. Ramnaraine, and D.C. Locke, Anal. Chim. Acta 55, $511,(2004)$

21. A. Profumo, D. Merli, and M. Pesavento, Anal. Chim. Acta 245, 539, (2005)

22. L. M. de Carvalho, P. C. do Nascimento, D. Bohrer, E. J. Pilau, R. Stefanello, and M. Lauer, Electroanal. 1081, 18, (2006)

23. R. Piech, and W. W. Kubiak, J. Electroanal. Chem. 59, 599, (2007)

24. L. M. Carvalho, P. C. do Nascimento, D. Bohrer, E. J. Pilau, R. Stefanello, and M. Lauer, Electroanal. 776, 20, (2007)

25. J. Kowalska, K. Chalko, and E. Stryjewska, Electroanal. 1508, 14, (2002)

26. C. Locatelli, and G. Torsi, J. Electroanal. Chem. 80, 509, (2001).

27. T. Tongesayi, and R.B. Smart, Electroanal. 434, 20, (2007)

28. W. Holak, Anal. Chem. 2189, 52, (1980)

29. C. M. Barra, and M. M. C. Dos Santos, Electroanal. 1098, 13, (2001)

30. M. A. Ferreira, and A. A. Barros, Anal. Chim. Acta 151, 459, (2002)

31. U. Grevlach, and G. Henze, Anal. Chim. Acta 217, 306, (1995)

32. F.T. Henry, T. O. Kirch, and T. M. Thorpe, Anal. Chem. 215, 51, (1979)

33. M.A. Reed and R. J. Stohberg, Anal. Chim. Acta 59, 3, (1987)

34. D. J. Myers, and J. Osteryoung, Anal Chem. 267, 45, (1973)

35. A. L. Allan y E. Rubio. Quim. Nova 14, 1, (1991) 